\title{
Talk, Listen, and Understand: The Impact of a Jazz Improvisation Experience on an Amateur Adult Musician's Mind, Body, and Spirit
}

\author{
Brent D. Rowan
}

\begin{abstract}
This paper examines the impact of creating music in an improvisational jazz style on an amateur adult musician's mind, body, and spirit. Learning jazz improvisation skills can help build more empathetic human beings, when the focus of improvisation is on reacting to what you hear in a clear and concise manner. Life skills are developed by focusing on deep listening and communicating with other musicians. Enabling a person to talk to, listen to, and understand those around them builds community and understanding, and lessens the likelihood of conflict. This allows growth and progress to take place in society, making the cultural capital built from a jazz improvisation program invaluable.
\end{abstract}

\section{Talk, Listen, and Understand}

Music is powerful. It is a part of our daily lives and major life events. It can energize sporting events, celebrate accomplishments, provide solace during tragedies, deliver reflection through life's journeys, and accompany other art forms. Music can affect the same person in many different ways and triggers emotional responses (Batt-Rawden, 2010), and all we have to do is listen. Active instead of passive listening can offer a completely different experience. What is the impact of music on those who are creating it (Limb, 2011)? My ongoing research seeks to explore some possible answers to these questions. No matter what the type of music or the people making it, there are some very important components to consider: who is creating the music, who is it for, and what was the motivation for its creation. These are critical factors in the emotional response generated by the music. This paper examines the impact of creating music in an improvisational jazz style on an amateur adult musician's mind, body, and spirit.

\section{Rationale}

It is my belief that teaching people to react in a musical way (requiring producing a sound you feel based on other sound and silence happening in a space) helps improve the way we listen and communicate with each other. Skillful improvisers can listen to the musicians around them and use their own voice to create a story with the people in their space. Music, specifically jazz improvisation, is not and should not be all about what one person creates; it should be about what that person creates with those around them. Listening to the other musicians can create an informed musical reaction. Expressing this creative reaction by clear and concise musical statements exposes channels of musical communication. Opening these channels lets the flow of emotional expression through the language of music to occur between the 
participants in the room (Lim, 2014). My goal in teaching jazz improvisation is to aid in the development of listening, enunciation, awareness, and empathy skills that will enrich and empower daily life. As a participant-researcher in this study, I believe that enabling a person to talk, listen to and understand those around them builds community and understanding, and lessens the likelihood of conflict. These skills allow growth and progress to take place in society, making the cultural capital built from a jazz improvisation program invaluable.

\section{Definitions}

New Horizons Band Guelph (NHBG) is an organization for amateur musicians that provides a fun and informative music-making opportunity for adults who have little or no musical experience, have been musically inactive for a period of time, or just love to play music. The Jazz Combo program is offered for members that want to learn about and play jazz improvisation styles and concepts.

A Jazz Combo for the purpose of this study is defined as a group of four to 10 instrumentalists with mainly traditional instrumentation (i.e., drums, bass, piano, guitar, and wind instruments). According to Merriam-Webster (2017) a combo is "1: a usually small jazz or dance band."

An Amateur Adult Musician is "one who engages in a pursuit, study, science, or sport as a pastime rather than as a profession" (Merriam-Webster, 2017), and in the context of this study is someone who has reached the age of majority and plays a musical instrument. The ability of amateur adult musicians varies.

Improvisation is instantaneously making up a melodic statement based on how the group plays the structure of a given song. The definition of improvise is:

"1: to compose, recite, play, or sing extemporaneously

2: to make, invent, or arrange offhand • the quarterback improvised a play

3: to make or fabricate out of what is conveniently on hand • improvise a meal" (Merriam-Webster, 2017).

\section{Methodology}

The 12 participants of the research were all members of the NHBG program who took part in a 10-week jazz improvisation combo program.

Data collection for this phenomenological study took part in three stages, with the goal of analyzing the impact of an experience. The first method, a focus group discussion, was held with nine participants and started with the question: "Would anyone like to share their perspective on what jazz improvisation is for them?" The topic of what improvisation is was also introduced, as well as what improvisation feels like in the moment. The focus group discussion lasted one hour and all members participated with open, friendly dialogue. I spoke very little except to keep the discussion focused around the topic of the 
experience of participating in a jazz improvisation ensemble. The discussion was transcribed, coded, and analyzed. The coding highlighted what thoughts, emotions, and reactions the participants expressed during the discussion. The analysis brought out two main themes. The first theme was how the experience feels to the participants, including how they personally benefit and why they continue to take part in the program. The second theme is the importance of the environment created and how it is managed. For a list of comments related to each of these themes, see the data section below. The focus group discussion was held after week 4 of the 10-week program.

The second data collection method took part in one-on-one interviews, held between weeks 6 and 9 . This generated more information about the personal experience of each individual while participating in a jazz improvisation combo. Discussion was held to understand the feelings and thoughts that the participants were having in this context. The following questions were asked to each interviewee:

1. Would you please start by describing the experience of improvising in a jazz combo.

2. Reflect on what improvising felt like the first time and how it feels now.

3. What are the thoughts in your mind as you are improvising with other musicians?

Keywords relating to mind, body, and spirit were extracted from these interviews. The frequency of these words was also noted, along with their relation to mind, body, and spirit (Table 1). The common thread through the interviews was each participant's positive experience and that the learning engaged their mind. The participants indicated that this music-making experience feels good and has a positive impact on the spirit.

The third method was an analysis of videotape from the jazz combo rehearsals. A checklist (see Appendix) was created to note various reactions during the rehearsals. Reactions were grouped into four categories: Facial, Physical, Vocal, and Musical. This data visually illustrated the discussion from the focus group and one-on-one interviews and was meant to show how the members reacted to learning and then how they reacted to a piece of music. The warm-up and first song played by the ensemble was recorded for 20 minutes on three consecutive weeks in the middle of the 10-week program. After analyzing the tape, I began to pay more attention to the members' reactions during rehearsal. It should be noted that the style, tempo, and complexity of the song affects how the members reacted physically. For example, faster tempi were more exciting, but often meant technical challenges; slower tempi relaxed the members. These types of observations and methods of data collection could comprise an entire study on their own. 


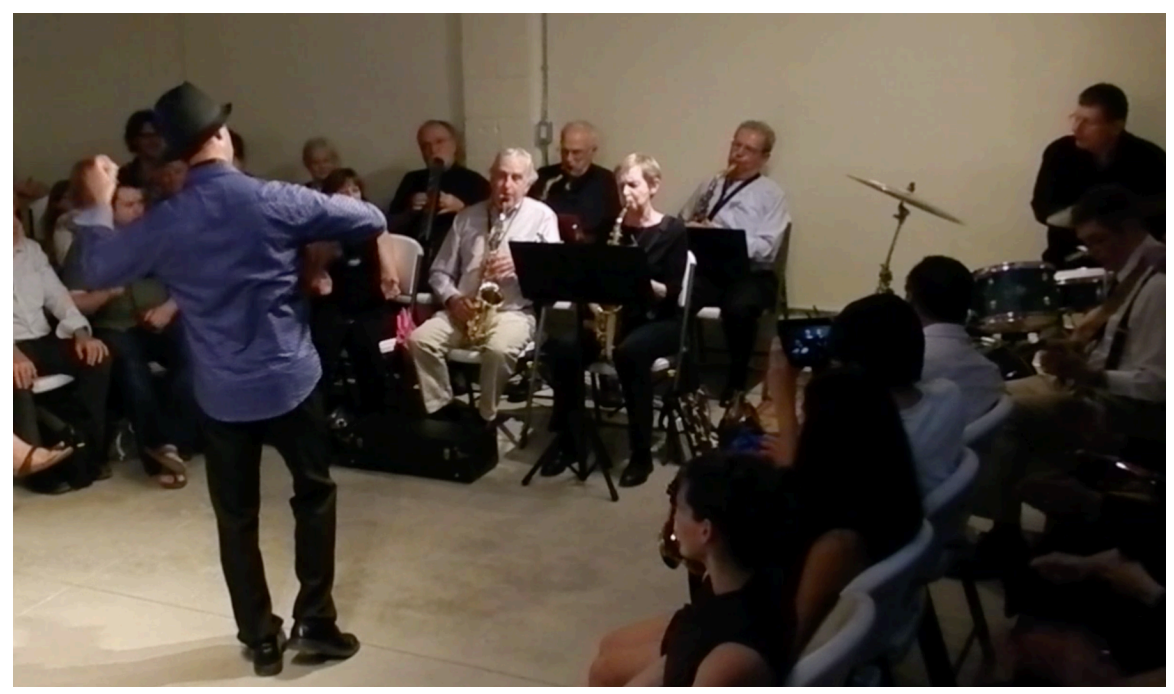

Fig. 1: Rehearsal

Click here for video of students rehearsing with Brent

\section{The Data}

The following is a list of quotations from the focus group that illustrates how participating in the program feels.

- It's something that I feel I can do;

- It is not a solitary activity;

- It's a weekly coming together with friends;

- You need this camaraderie to help you, I don't care how good you are;

- You depend on each other;

- The most wonderful thing for me... is the community aspect of things;

- To have that sense of community with a bunch of like-minded people;

- Everybody is encouraging one another;

- Everybody roots for each other;

- You are in there enjoying the music and you are in a different and wonderful place; and

- I am completely enjoying the experience.

The following is a list of quotations from the focus group that illustrates the importance of the environment and how it is managed.

- This is a fun way to learn;

- No one is there criticizing;

- I think of it as group therapy;

- It's a really good attitude;

- I definitely come out of the sessions on a high;

- Being given permission to be vulnerable ${ }^{1}$; 
- Very encouraging environment...so it is really important to have an environment where you can take the risk and then when you have the validation then you are more liable to take a bigger risk the next time which is what you need to do to grow; and

- I am completely enjoying the experience and I would echo what everyone here has said and that is that you're a wonderful teacher and a very fine conductor.

Keywords taken from one-on-one interviews were grouped according to their relationship to Mind, Body, or Spirit. Examples of keywords are shown in Table 1.

Table 1

Categories of keywords from one-on-one interviews

\begin{tabular}{|c|c|c|}
\hline Mind & Body & Spirit \\
\hline adventure, anxiety, challenging, & age, keep active, relaxed & awareness, awesome, being a kid, \\
\hline committed, communicate, comparison, & & companionship, camaraderie, do no \\
\hline confidence, copy, counting, creating, & & wrong, do something for me, enjoy, \\
\hline difficult, engaged, hard, hear, imitating, & & experience, feel, freedom, friends, fun, \\
\hline language, learn, listen, making, mental & & good vibe, incentive, influence, laughing, \\
\hline challenge, methodology, mistakes, & & like, natural, no judging, open the door, \\
\hline nervous, patterns, problem, process, & & permission, powerful, safety, scary, \\
\hline realize, respond, story, structure, thinking, & & social, successful \\
\hline try, understanding, work, wrong & & \\
\hline
\end{tabular}

These words were also categorized as positive or negative. Ninety-one percent of the categorized words spoken were considered positive in nature.

The word mentioned the most times in interviews and focus group discussion was "learning". Adults like to learn; or, at the very least, the jazz combo participants seem to take part in the group because they want to engage, learn, and keep their mind active. During the one-on-one interviews, many of the members wanted to talk about what they were thinking during the improvisation sessions. One retired teacher who would often share with me her analysis of what we were doing and why, remarked during the interview that she felt like she got more therapeutic value out of the jazz improvisation combo experience than going to see her therapist. I realized later that for her this was a Community Music Therapy experience and the improvising helped her express what she was feeling as she was suffering from a long battle with cancer. All the participants came having an interest in learning about jazz improvisation. A few members were quite skilled in other styles or with other instruments. Before starting in this group, they were able to hear musical ideas in their heads, but could not always get the ideas to their instrument in the moment. One member joined the group hoping to develop a deeper connection to another artistic discipline. As a dancer, he always had a strong relationship with movement and beat, 
but felt through participation in this program he was able to learn more about the rhythmic components of music, which allowed for growth in his dancing.

Table 2 illustrates observations of keywords from the videotape and how they related to Mind, Body, or Spirit.

Table 2

Categories of observed keywords and number of occurrences from videotape checklist (see Appendix)

\begin{tabular}{|c|c|c|c|c|c|}
\hline Mind & & Body & & Spirit & \\
\hline Facial & $\begin{array}{c}\# \\
\text { occ }\end{array}$ & Facial & $\begin{array}{c}\# \\
\text { occ }\end{array}$ & Facial & $\begin{array}{c}\# \\
\text { occ }\end{array}$ \\
\hline Frustration & 4 & & & Smile & 82 \\
\hline Look lost & 0 & & & Frown & 3 \\
\hline Look confused & 3 & & & Reaction to good feel & 1 \\
\hline Look content/accomplished & 10 & & & & \\
\hline Made a theory connection & 5 & & & & \\
\hline \multirow[t]{2}{*}{ Made a musical connection } & 5 & & & & \\
\hline & $\begin{array}{c}\# \\
\text { occ }\end{array}$ & Physical & $\begin{array}{c}\# \\
\text { occ }\end{array}$ & Physical & $\begin{array}{c}\# \\
\text { occ }\end{array}$ \\
\hline \multirow[t]{3}{*}{ Frustration } & 2 & Moving to the groove & 12 & Hearing the music & 0 \\
\hline & & Reaction to good feel & 3 & Played with confidence & 0 \\
\hline & $\#$ & & $\#$ & & $\#$ \\
\hline Vocal & occ & Vocal & occ & Vocal & occ \\
\hline Frustration & 1 & Reaction to good feel & 5 & Laughter & 40 \\
\hline Question asked to clarify & 8 & & & Silence & 0 \\
\hline Question asked for more info & 3 & & & & \\
\hline Comment made to "show off" & 4 & & & & \\
\hline \multirow[t]{2}{*}{ Talked off topic } & 4 & & & & \\
\hline & $\#$ & & $\#$ & & $\#$ \\
\hline Musical & occ & Musical & occ & Musical & occ \\
\hline Frustration & 2 & & & Play by feel not theory & 2 \\
\hline Silence & 0 & & & Made a musical connection & 1 \\
\hline Loud noise & 0 & & & & \\
\hline Speak clear idea & 5 & & & & \\
\hline Copy an idea & 16 & & & & \\
\hline Respond to an idea & 19 & & & & \\
\hline Idea stated and copied & 9 & & & & \\
\hline Play by theory not feel & 8 & & & & \\
\hline Playing-not listening/engaging & 2 & & & & \\
\hline Played with confidence & 11 & & & & \\
\hline Made a theory connection & 10 & & & & \\
\hline
\end{tabular}




\section{Discussion}

When analyzing the videotape, there was a great deal of laughter and smiling, listening and engagement from the participants, showing the group's cohesion and camaraderie. The videotape also displays some notable "light bulb turning on" moments that show how the brain gets working (Rettner, 2010). Members are seen nodding to each other with understanding and acknowledgment as they are playing music together. The videotape also shows that playing a musical instrument involves a certain amount of physical exertion, which is good for our health (Blackwell, 2006). Through videotape observations it seems clear that participating in a jazz improvisation combo offers people a chance to keep their mind and body active and engages their spirit.

The jazz program is set up to allow a balance between freedom and structure, so that members who have had formal training can enjoy the freedom to create parts within a comfortable structure, and members with little formal training can enjoy the structure while still experiencing freedom to explore the environment. During the focus group, a number of members mentioned that if an environment is poorly managed and the morale of the group is low, they would prefer not to participate. The morale of this group is high: laughter, for example, was recorded 65 times in the 60-minute focus group discussion. A sense of belonging to the group, camaraderie, and feeling heard were also mentioned many times. The structure of a program and the management of the environment the program is implemented in are two of the most important elements that affect the experience of a participant.

In order for a group to feel comfortable and allow learning to happen, slowly introduce small, safe risks until the group feels comfortable enough to take bigger risks. It is important for the facilitator to create a fun, relaxed environment to allow some freedom and self-expression and empower the participants to listen.

The comments made by the participants during the focus group have revealed a nonformal (Higgins \& Willingham, 2017) way of learning. With this type of environment, there is structure but there is a great deal of freedom within that structure. This allows for a less stressful learning environment, in which we can have fun with friends in a nonjudgmental forum where risks are encouraged and supported. This motivates learning and engages the mind, while encouraging vulnerability and personal and musical growth. We are also learning to unlock some of the mysteries of how jazz improvisation works. For many adults, previous music learning experiences were very structured and had a rigid formality which often tended to be something that is unlikely to be described as fun. The freedom to move around and explore within a semi-structured environment provides a feeling of comfort, but there is still some guidance. Life skills are developed by focusing on deep listening and communicating with other musicians. The musicians become in sync with each other by learning how to work together.

Developing a need for each other, bringing the group together, and allowing time for developing group camaraderie creates a rewarding and somewhat therapeutic experience. The group members are supportive of one another because of their similar age, experiences, and motivations to learn, however some participants are still affected by peer pressure within the group. There is the opportunity to work 
on your own between sessions, then come together and express yourself in a supportive place. It is a space to be creative; the group effort gives pleasure and a positive experience. It becomes a place where the members can have their own voice and experience the feeling of doing something new, exciting, and fun. Being themselves is encouraged and leads to opportunities for personal growth. Learning a bit of music theory gives the members something to strive toward, and listening to examples or modeling helps them understand the goals. Listening to each other and being aware of how the music is working allows for a deeper understanding and more fulfilling musical experience.

\section{How Does the Data Align With My Beliefs?}

Open the door and invite people to participate in a non-judgmental, safe, and supportive environment (Higgins, 2012). The leader must welcome the participants and have fun. The fun and laughter will create a positive group feeling and allow for learning, exploration, and growth. As the facilitator for NHBG Jazz, my approach is to try to learn by having fun. The word "fun" can take on many meanings, but for the purposes of working with this group of people, I think of fun as a way to make the time spent together as a group an enjoyable experience. We laugh, smile, tell stories, and develop friendships. The regular members of the band are not there to train themselves to become professional musicians; they are there for the social aspect, the learning opportunity, and, simply put, they just want to have a good time. When these social components are present, growth of the person, not just growth of the musician, also occurs. Jazz improvisation is a complex activity. The mind is engaged, the body is active, and the spirit is nurtured (Cohen, 2002; University of Maryland Medical Center, 2008). Under empathetic management and a nonjudgmental environment, a jazz improvisation setting can have a positive impact on the flourishing mind, body, and spirit experience.

\section{Summary and Implications}

Mentioned numerous times throughout this study was the idea of a safe place to play wrong notes (i.e., creating a nonjudgmental atmosphere). It is important to let people try something and not feel judged. The environment was also fun and light; this was intentional as I feel that learning happens better when the mind is laughing (McKay \& Moser, 2005). Who the facilitator is and how they structure the program and deliver the information is very important. As outlined by Frank J. Barrett (1998) in his article Creativity and Improvisation in Jazz and Organizations: Implications for Organizational Learning, giving the members the right amount of information, but then providing them with time to explore and figure it out is essential. Developing good morale in the group and setting up a supportive environment is also critical. One of the largest challenges is understanding the various personalities and managing egos in the room

to ensure a safe, supportive, and enriching environment. I feel that the facilitator needs to be the conductor of the energy (Bartlett, 2007) in the room-the music will take care of itself!

Participation in jazz ensembles with the NHBG program under my direction is fun. The members join the program and stay in the program because they enjoy it. They feel their minds are engaged as they are 
learning in a safe, supportive, and encouraging environment. The environment is managed carefully to provide the opportunity to learn, but in a way that is enjoyable. The amateur adult musician is usually not someone who is training for a career to make a living playing music. It is someone who already has learned how to work hard at something to achieve results and is now looking for an enjoyable activity that allows them to learn about jazz. The tools I am using to provide this opportunity are respect, dedication, and support of the music and each other. We must learn how to listen to each other and speak in a clear and concise manner so that we can understand how to create music together. I call this my Talk, Listen, and Understand mantra and I believe that we are more aware and empathetic human beings if we follow this directive.

The improvisation experience is more fulfilling when it is an interactive experience with everyone in the combo engaging and filling a role (Griffiths, 2014). When the members react musically and physically to each other, there is a more supportive and encouraging environment where risks can be taken and growth can occur. Listening to each other helps develop awareness skills and an understanding of what each other is doing. An increase in awareness can lead to an increase in developing empathy. Listening to what another person does with the same information (provided the environment is encouraging and supportive) helps build a sense of cohesion in the group. Members feel like we are all in this together: learning and exploring with awareness of what each person is doing.

The following two quotations from the focus group illustrate the impact jazz improvisation can have on an amateur adult musician: "Improv is like a life skills...I want to listen and I want to have those life skills", and "Improvisation is the nature of existence...music is so much a part of the human existence".

\section{Next Steps}

This program has been running for one year at the time of writing this paper, so it is relatively new. I am interested to see what happens over time; specifically, what will keep the members coming. Will jazz improvising continue to be the thing that keeps these people active or is it just something new that fills that need for now?

As part of a presentation of this research, a performance was held called the "Convergence of Life." Professional musicians, youth musicians, members of the NHBG jazz program, dancers, and a spoken word artist were all brought together to show how various demographics and disciplines can work together. The event was set up in a way to create interaction and engagement between the audience and the performers. At the end of the evening, the entire room was moving spontaneously to the music with lots of smiles. The members of NHBG had an enjoyable experience performing in front of a room full of new listeners. Their anxiety level seemed lower than usual, and at the next day's rehearsal the group seemed to interact together much more deeply than the previous week. The positive experience of the performance brought them closer together. Sharing the experience of music making with others could then be the next step in a completely fulfilling experience (Brooks, 2013; Sodhi, 2011) that adds to the cultural capital of a community. 
My approach to teaching improvisation focuses on listening to everyone else in the room, playing your own part clearly so that it can be listened to, and reacting to the interactions that result from this listening and clear speaking. The listening is done with the ears and eyes; the clear speaking is done with the instrument, body language, and facial expressions. Gary Diggins (2016) outlines this style of facilitation in his book, Tuning the Eardrums: Listening as a Mindful Practice

By means of silent body language, facial features, interruption, correction, suggestive questions, or energetic reactions, it is possible for a listener to subliminally steer or influence a speaker's narrative... The circle we create of sharing must be free of impatience, free of demand, and certainly free of judgement. (p. 120)

If the skills of listening and speaking clearly can be improved, then a deeper understanding of each other can be attained. My hope is that a Talk, Listen, and Understand mantra will grow from the jazz improvisation setting and influence daily life. When it does, we are creating more empathetic people with a greater awareness of their environment and a greater understanding of how to exist harmoniously within that environment.

\section{Note}

1. My interpretation of this quote is based on the belief that we create a space where people can feel safe enough to take a chance without being criticized. It is not just because they are adults; I watch them still get stage fright and be shy about playing in front of others, but over time in this environment they relax and feel safe enough to try something new!

\section{References}

Amateur. (2017). In Merriam-Webster.com.

Retrieved from https://www.merriam-webster.com/dictionary/amateur

Barrett, F.J. (1998). Creativity and improvisation in jazz and organizations: Implications for organizational learning. Organization Science, 9(5), 605-622.

Retrieved from http://dx.doi.org/10.1287/orsc.9.5.605

Bartlett, R. (2007). Matrix energetics: The science and art of transformation. Hillsboro, OR

Batt-Rawden, K. (2010). The role of music in a salutogenic approach to health. The International Journal of Mental Health Promotion. 12(2), 11-18. Retrieved from

http://www.ingentaconnect.com/search/article?option 1 =tka\&value1=listening+AND+health+AND+mu sic\&sortDescending=true \&sortField=default\&pageSize $=10 \&$ index $=7$

Blackwell Publishing Ltd. (2006, June 22). Music thought to enhance intelligence, mental health and immune system. ScienceDaily.

Retrieved from www.sciencedaily.com/releases/2006/06/060622172738.htm

Brooks, M. (2013, November 18). More evidence that music benefits the brain, Medscape. Retrieved from http://www.medscape.com/viewarticle/814540 
Cohen, A. J. (2002). Psychomusicology: A journal of research in music cognition. APA Psychnet, 18(12), 3-9. Retrieved from http://ojs.vre.upei.ca/index.php/psychomusicology/issue/view/pmmb18

Combo. (2017). In Merriam-Webster.com.

Retrieved from https://www.merriam-webster.com/dictionary/combo

Diggins, G. (2016). Tuning the eardrums: Listening as a mindful practice. Victoria, Canada: Friesen Press.

Griffiths, S. (2014, June 6). Is jazz a form LANGUAGE? Brains of improvising musicians work in the same way as when people think about words, Daily Mail. Retrieved from http://www.dailymail.co.uk/sciencetech/article-2650805/Is-jazz-form-LANGUAGE-Brains-improvisingmusicians-work-way-people-thinking-words.html

Higgins, L. (2012). Community music: In theory and in practice. New York: Oxford University Press.

Higgins, L., \& Willingham, L. (2017). Engaging in community music: An introduction. New York: Routledge.

Improvise. (2017). In Merriam-Webster.com.

Retrieved from https://www.merriam-webster.com/dictionary/improvise

Lim, A. (Associate Producer). (2014, February 28). Your brain on jazz [Audio Podcast]. Retrieved from http://www.sciencefriday.com/segment/02/28/2014/your-brain-on-jazz.html

Limb, C. (2011, January). Your brain on improv [Video File] Retrieved from https://www.ted.com/talks/charles_limb_your_brain_on_improv/transcript?language=en

McKay, GA., \& Moser, P. (2005). Community music: a handbook, Dorset: Russell House.

Rettner, R. (2010, July 20). Music 'tones the brain,' improves learning, Live science. Retrieved from http://www.livescience.com/9964-music-tones-brain-improves-learning.html

Sodhi, P. (2011, May 10). Healing the mind with music, The Times of India. Retrieved from http://timesofindia.indiatimes.com/city/delhi/Healing-the-mind-withmusic/articleshow/8213088.cms?referral=PM

University of Maryland Medical Center. (2008, November 12). Joyful music may promote heart health. ScienceDaily. Retrieved from www.sciencedaily.com/releases/2008/11/081111182904.htm

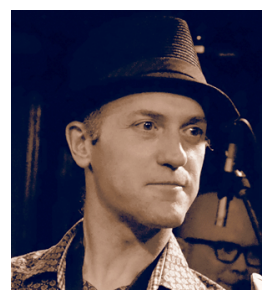

Brent Rowan is a professional community musician, a saxophonist performing in a variety of musical collaborations; including Juno Nominated Eccodek, Big Bands, jazz combos, and creative music ensembles. Brent has performed at music festivals all across Canada, the UK, and Germany. Three albums of his own compositions are: "It's About Time" (2006), "IZ" (2012), and "Where is Local" (2016). Brent composes and arranges music and is the founding director of the Guelph Youth Jazz Ensemble and the New Horizons Band for Guelph, and is the conductor of the Cambridge Concert band. Brent teaches in the Community Music Program at Wilfrid Laurier University and at his private music studio.

Photo credit: Gee Wong 


\section{Appendix}

\section{Observational Reaction Checklist}

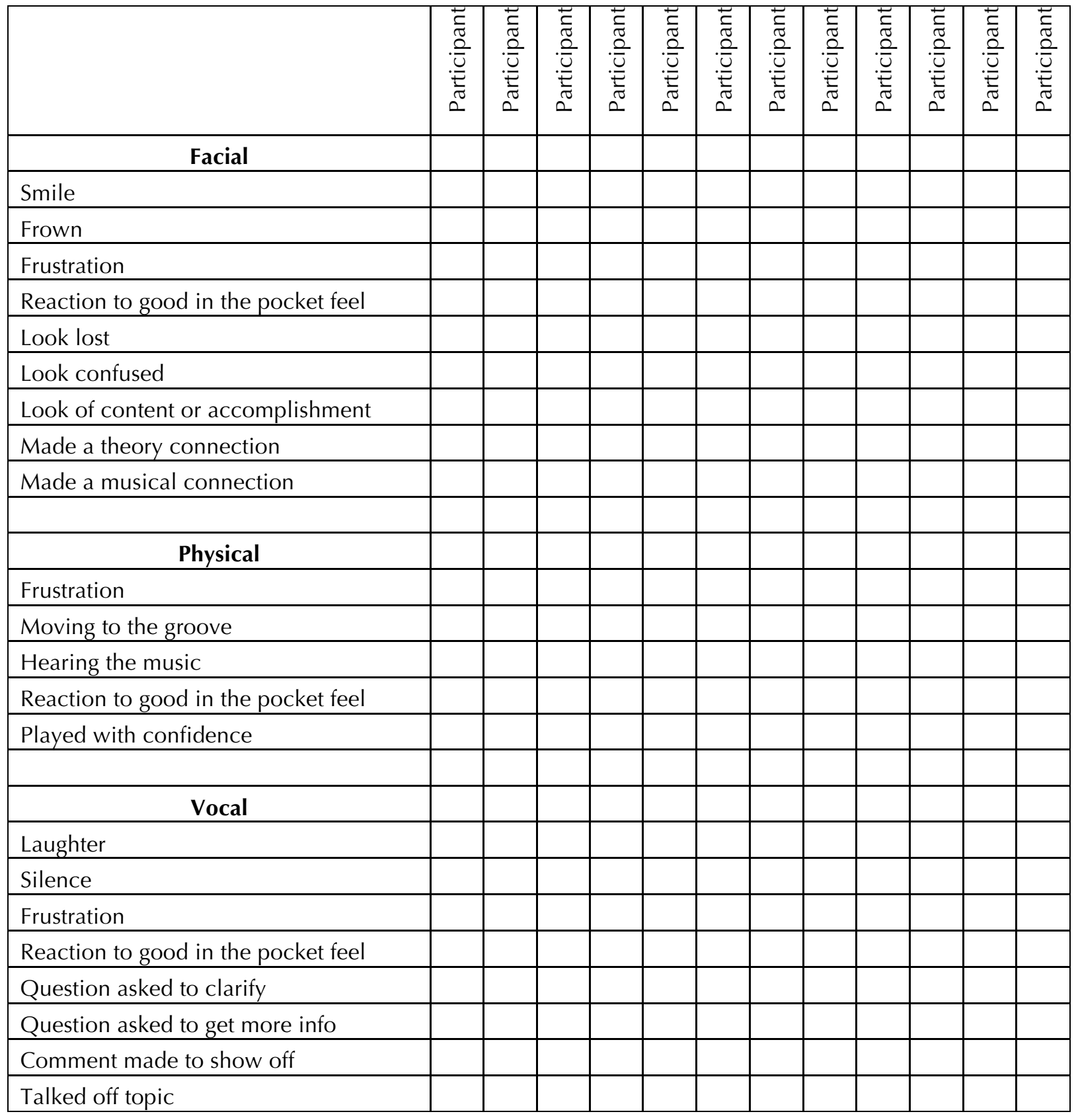




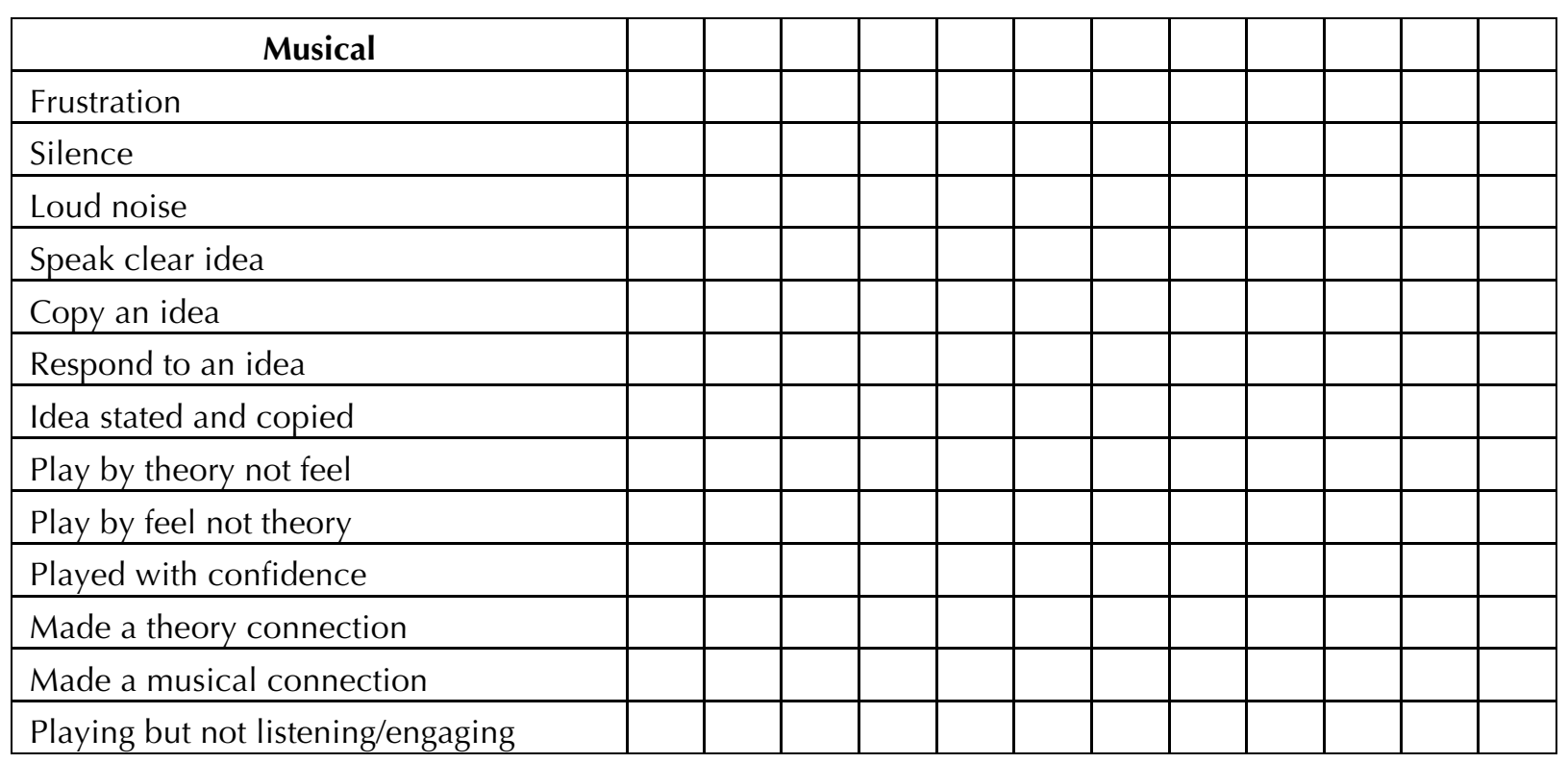

